\title{
Knowledge, attitudes and practices of barbers about hepatitis B and C transmission in Hyderabad, Pakistan
}

A.H. Jokhio, ${ }^{1}$ T.A. Bhatti ${ }^{2}$ and M.S. Memon ${ }^{3}$

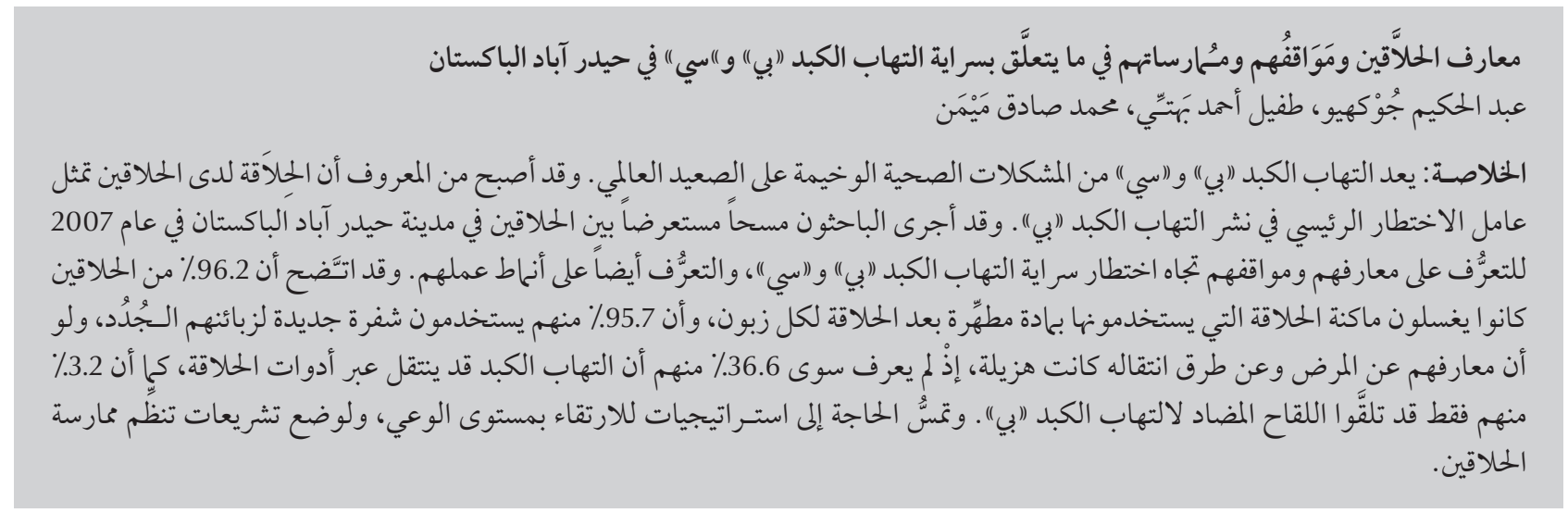

ABSTRACT Hepatitis B and C virus (HBV/HCV) infections are serious global health problems. Shaving by barbers has been identified as the key risk factor for spread of HBV. We conducted a cross-sectional survey of barbers in Hyderabad city, Pakistan in 2007 to establish their knowledge and attitudes to the risk of HBV and HCV transmission and their working patterns. Observations showed that $96.2 \%$ washed razors with antiseptic after each client and $95.7 \%$ used a new blade with new clients. However, knowledge about the diseases and modes of transmission were poor and only $36.6 \%$ knew that hepatitis can be transmitted via shaving instruments. Only $3.2 \%$ of 186 barbers were vaccinated against HBV. Strategies are needed for raising awareness and regulations of barbers' practices.

\section{Connaissances, attitudes et pratiques des barbiers concernant la transmission de I'hépatite B et C à Hyderabad (Pakistan)}

RÉSUMÉ Les infections par les virus de l'hépatite B et C constituent de graves problèmes de santé dans le monde. Le rasage par les barbiers a été identifié comme étant le principal facteur de risque de propagation du virus de I'hépatite B. Nous avons effectué une étude transversale auprès des barbiers de la ville d'Hyderabad (Pakistan) en 2007 afin d'identifier leurs connaissances et leurs attitudes dans le domaine du risque de transmission des virus de l'hépatite B et C ainsi que leurs méthodes de travail. Les observations ont révélé que 96,2 \% d'entre eux lavaient les rasoirs avec un antiseptique après chaque client et qu'ils étaient 95,7 \% à utiliser une lame neuve pour chaque client. Mais leur connaissance de ces maladies et de leur mode de transmission était faible et seuls $36,6 \%$ d'entre eux savaient que l'hépatite pouvait se transmettre par des instruments de rasage. Seuls 3,2\% des 186 barbiers étaient vaccinés contre le virus de l’hépatite B. Des stratégies de sensibilisation aux pratiques des barbiers et de réglementation de ces dernières sont nécessaires. 


\section{Introduction}

Globally over 2 billion people have been infected with hepatitis B virus (HBV) [1] and an estimated 170 million people are chronically infected with hepatitis $\mathrm{C}$ virus (HCV) [1,2]. In Pakistan specific estimates for the prevalence of both diseases range from $2 \%-10 \%[3,4]$. Recently the rates of HBV infection in the country have been increasing, attributed to a lack of proper health facilities, low socioeconomic status and low public health awareness about the transmission of communicable diseases [5]. A significant proportion of those exposed to HBV become chronically infected and are at considerable risk of liver cancer, chronic active hepatitis and cirrhosis. These infected people may not be aware of their HBV status and are not clinically ill but are a source of infection to others.

$\mathrm{HBV}$ is 50 to 100 times more infectious than HIV, yet is transmitted by contact with blood or body fluids of an infected person in the same way as HIV [1]. Razor shaving by barbers has been identified as a key risk factor for transmission of HBV [6] and HCV $[7,8]$. In Turkey $39.8 \%$ of barbers were found to be HBV positive and many were infected during the course of employment [9]. HBV and $\mathrm{HCV}$ infections have been implicated as an occupational hazard of the barbers' trade in several developing countries [10-18]. In Pakistan, daily facial shaving and armpit shaving from barbers has been identified as a risk factor for transmission of HBV and HCV [14-17].

Preventionis the beststrategyagainst the epidemic of viral hepatitis. Barbers have low awareness about hepatitis and the risk of transmission of infectious agents by reuse of razors and scissors on multiple clients $[19,20]$. In Pakistan the prevalence of shaving by barbers is reported to be as high as 34\%-49\% of the male population [14] and it is important to know how barbers perceive the risks in relation to prevention of transmission between themselves and customers. A very limited number of studies have been published in Pakistan investigating knowledge, attitude and practices about hepatitis transmission among barbers [19] and patients attending family medicine clinics [21]. We therefore designed the current study to assess the knowledge, attitudes and common practices of barbers in Hyderabad city, Sindh province regarding risk of transmission of HBV and HCV in their work. This information will help to guide the design and implementation of appropriate prevention and interventions strategies.

\section{Methods}

This study was part of cross-sectional study conducted in Hyderabad to determine the prevalence and risk factors of HBV and HCV infection among barbers and their regular clients. Hyderabad is the 4th largest city in Pakistan and 2nd largest city in Sindh province and about $200 \mathrm{~km}$ from Karachi, which has a mix of both low and high socioeconomic residents.

\section{Sample}

There were 521 barbers shops registered in the city. Hyderabad city was divided into 11 zones and all the barbers shops were listed using the mapping exercise carried out by the Canadian International Development Agency project for HIV/AIDS serosurveillance. Using a computer-generated, simple, random sampling procedure, 10 shops were selected from each zone to achieve the target sample size for the original crosssectional study. From the selected 111 shops, there were 202 barbers available and eligible for interview. After giving informed verbal consent, 186 barbers agreed to participate in the study and were included in the final analysis; the refusal rate was $8 \%(16 / 202)$.

\section{Data collection}

The survey was completed during March-October 2007. Trained medical interviewers visited the selected barbers' shops and requested barbers to participate in the study. Face-to-face interviews were conducted with participating barbers about their knowledge and attitudes. Before the start of the main interview, one of the accompanied supervisors not involved in data collection observed the barber and assessed his instrument use practices with clients.

The questionnaire collected data about personal characteristics such as age, education, income, marital status, ethnic group and area of residence. The knowledge section covered barbers' knowledge about different modes of transmission of hepatitis, including the risk of transmission of the disease due to use and reuse of razors, and knowledge of vaccines for HBV and HCV. The attitudes section covered the type of media they use for information and entertainment; attitudes towards these diseases; whether they had been vaccinated against these diseases; whether they were a substance abuser, had had a blood transfusion, tattoos or surgical operation/stitches; and whether they thought it was necessary to have periodic screening for bloodborne diseases in general and whether they themselves would like to be tested for these diseases.

The practices of barbers were observed on 2 occasions while they were attending clients and a checklist was used to record: hand-washing before each client; sterilization of instruments with antiseptic; use and reuse of blades; and disposal of used blades and instruments.

A random selection of $10 \%$ of the questionnaires was checked to verify whether all questions had been understood by the barbers. Participation in the survey was on a voluntary basis. 
The study was approved by the ethical review committee of Liaquat University of Medical and Health Sciences.

\section{Analysis}

A Microsoft Access 2000 database was used for data entry and the data were tabulated and analysed by frequency distributions in SPSS, version 11.5.

\section{Results}

A total of 186 questionnaires were completed from barbers' interviews. The participant's demographic characteristics are shown in Table 1. Most respondents $(69.9 \%)$ were aged $15-30$ years. Around one-third (35.5\%) of barbers were illiterate and another $41.9 \%$ had education up to primary school. Nearly half $(53.2 \%)$ of the respondents were unmarried. Most respondents (95.7\%) were resident in the main urban areas and the largest ethnic group in terms of mother tongue was Urdu (47.8\%).

\section{Knowledge}

Responses to the knowledge questions showed that awareness of modes of transmission of hepatitis and the different sources/risk factors were low, ranging from only $9.7 \%$ correct for foodborne transmission to $36.6 \%$ who knew that hepatitis can be transmitted through barber's shaving instruments (Table 2). Only $11.3 \%$ of respondents knew that both HBV and HCV have the same mode of transmission and $6.5 \%$ knew that there is a vaccine that can protect against $\mathrm{HBV}$, while $8.1 \%$ thought there was a vaccine for $\mathrm{HCV}$.

\section{Attitudes}

Only $3.2 \%$ of respondents reported that they had been vaccinated against hepatitis B virus. (Table 3) Three-quarters (74.7\%) had not seen any information or radio/television programmes on these or other bloodborne diseases. Most barbers (90.3\%) did not agree that it was essential to have periodic

\begin{tabular}{|c|c|c|}
\hline Characteristic & No. & $\%$ \\
\hline \multicolumn{3}{|l|}{ Age (years) } \\
\hline $15-20$ & 50 & 26.9 \\
\hline $21-30$ & 80 & 43.0 \\
\hline $31-40$ & 28 & 15.1 \\
\hline$>40$ & 28 & 15.1 \\
\hline \multicolumn{3}{|l|}{ Education (no. of years) } \\
\hline Illiterate & 66 & 35.5 \\
\hline Primary $(\leq 5)$ & 78 & 41.9 \\
\hline Intermediate $(\leq 12)$ & 40 & 21.5 \\
\hline Higher/university $(\geq 14)$ & 2 & 1.1 \\
\hline \multicolumn{3}{|c|}{ Monthly income (Pakistan rupees) } \\
\hline $2000-4000$ & 20 & 10.8 \\
\hline$>4000-5000$ & 71 & 38.1 \\
\hline > 5000-10000 & 91 & 48.9 \\
\hline$>10000$ & 4 & 2.2 \\
\hline \multicolumn{3}{|l|}{ Marital status } \\
\hline Married & 87 & 46.8 \\
\hline Single & 99 & 53.2 \\
\hline \multicolumn{3}{|l|}{ Mother tongue } \\
\hline Sindhi & 56 & 30.1 \\
\hline Urdu & 89 & 47.8 \\
\hline Punjabi & 23 & 12.4 \\
\hline Baluchi & 1 & 0.5 \\
\hline Pashto & 2 & 1.1 \\
\hline Saraki and others & 15 & 8.1 \\
\hline \multicolumn{3}{|l|}{ Residence } \\
\hline Urban & 178 & 95.7 \\
\hline Semi-urban & 1 & 0.5 \\
\hline Rural & 7 & 3.8 \\
\hline
\end{tabular}

screening tests for bloodborne diseases in the population; however, $97.8 \%$ would themselves like to be tested for these infections: around one-quarter (24.7\%) reported a history of substance abuse (Table 3).

\section{Practices}

Observations of barbers' practices showed that $68.8 \%$ washed their hands before attending each client, $75.8 \%$ cleaned instruments with disinfectant between clients, $60.2 \%$ washed their instruments after shaving the clients, $72.0 \%$ washed razors with tap water before use on a new client, $96.2 \%$ also washed razors with an antiseptic solution after every use, $95.7 \%$ used a new blade on new clients and $39.2 \%$ used disinfectants for skin cuts (Table 4). About one-third (34.9\%) of barbers disposed of used blades in the regular garbage system.

\section{Discussion}

The current study has described barbers' knowledge about the transmission of HBV and HCV and provides an outline for further studies. The results show low awareness about the different modes of transmission of $\mathrm{HBV}$ and 


\begin{tabular}{|c|c|c|c|c|}
\hline \multicolumn{5}{|c|}{$\begin{array}{l}\text { Table } 2 \text { Barbers' knowledge about hepatitis B and C virus diseases and their mode } \\
\text { of transmission }(n=186)\end{array}$} \\
\hline \multirow[t]{2}{*}{ Knowledge item } & \multicolumn{2}{|c|}{ Yes } & \multicolumn{2}{|c|}{ No } \\
\hline & No. & $\%$ & No. & $\%$ \\
\hline \multicolumn{5}{|l|}{ Mode of transmission } \\
\hline Contaminated water & 23 & 12.4 & 163 & 87.6 \\
\hline Food & 18 & 9.7 & 168 & 90.3 \\
\hline Shared utensils & 25 & 13.4 & 161 & 86.6 \\
\hline Sexual contact & 67 & 36.0 & 119 & 64.0 \\
\hline Intravenous drug use & 41 & 22.0 & 145 & 78.0 \\
\hline Reuse of needles & 59 & 31.7 & 127 & 68.3 \\
\hline Blood transfusion & 54 & 29.0 & 132 & 71.0 \\
\hline Dental procedures & 38 & 20.4 & 148 & 79.6 \\
\hline Scissors/surgical instruments & 46 & 24.7 & 140 & 75.3 \\
\hline Tattooing & 39 & 21.0 & 147 & 79.0 \\
\hline Barbers' shaving instruments & 68 & 36.6 & 118 & 63.4 \\
\hline Ear/body piercing & 39 & 21.0 & 147 & 79.0 \\
\hline $\begin{array}{l}\text { Hepatitis B and C have the same mode } \\
\text { of transmission }\end{array}$ & 21 & 11.3 & 165 & 88.7 \\
\hline \multicolumn{5}{|l|}{ Protection } \\
\hline $\begin{array}{l}\text { A vaccine can protect the individual } \\
\text { against hepatitis B infection }\end{array}$ & 12 & 6.5 & 174 & 93.5 \\
\hline $\begin{array}{l}\text { A vaccine can protect the individual } \\
\text { against hepatitis } C \text { infection }\end{array}$ & 15 & 8.1 & 171 & 91.9 \\
\hline
\end{tabular}

HCV diseases, even though the majority of barbers were from the 4th largest city in Pakistan. The majority of study participants had the misconception that these diseases were not transmitted by contact with the blood of an infected person, via blood transfusion, reuse of needles or through barbers' shaving instruments.

Only $9.7 \%-36.6 \%$ of respondents knew about the different modes of transmission of hepatitis and the risk factors. This is similar to another study in which $13 \%$ of barbers in Rawalpindi and Islamabad urban cities in 1999 reported having knowledge of HBV and HCV [19]. Knowledge about specific routes of $\mathrm{HBV}$ transmission was also similar to the previous study. For example, $7 \%$ of barbers in Rawalpindi/ Islamabad knew that HBV could be prevented by vaccination (compared

\begin{tabular}{lrrrr}
\hline Table 3 Barbers' attitudes about hepatitis B and C virus diseases $(\boldsymbol{n}=\mathbf{1 8 6})$ \\
\hline & \multicolumn{3}{c}{ Yes } & \multicolumn{3}{c}{ No } \\
Attitude item & No. & $\%$ & No. & $\%$ \\
$\begin{array}{l}\text { Seen television/radio programmes on } \\
\quad \text { these or other bloodborne diseases }\end{array}$ & 47 & 25.3 & 139 & 74.7 \\
$\begin{array}{l}\text { Agree with periodic screening for } \\
\quad \text { bloodborne diseases }\end{array}$ & 18 & 9.7 & 168 & 90.3 \\
Agree to be personally tested for these & 182 & 97.8 & 4 & 2.2 \\
$\quad$ infections & 6 & 3.2 & 180 & 96.8 \\
Is vaccinated against hepatitis B & 46 & 24.7 & 140 & 75.3 \\
Is currently substance abuser & 3 & 1.6 & 183 & 98.4 \\
Has had blood transfusion & 4 & 2.2 & 182 & 97.8 \\
Has had tattoos & 22 & 11.8 & 164 & 88.2 \\
Has had surgical operation or stitching & & &
\end{tabular}

with almost the same proportion of barbers in the current study), and 13\% of barbers in Rawalpindi/Islamabad were aware of the risk of transmission of hepatitis through the intravenous route (compared with $22.0 \%$ of barbers in Hyderabad). However, more of our barbers (36.6\%) were aware that hepatitis can be transmitted through barbers' shaving instruments compared with only $12.5 \%$ in the previous study.

Although mass media campaigns regarding these diseases and $\mathrm{HBV}$ immunization had been introduced in Pakistan, they seem to have had a low impact concerning knowledge of HBV immunization. It may be that poor people cannot afford to avail themselves of the opportunity for vaccination and therefore are less likely to be aware about immunization. This could also be because these infections are perceived to be common diseases in Pakistan.

Only $4.3 \%$ of barbers reused blades on different clients and $13.4 \%$ reused blades on the same clients for armpit shaving without antiseptic cleaning. However, is possible that they were aware of being observed during data collection and that the $65.1 \%$ of barbers who did not dispose of used blades in the bin may have been intending to reuse them later on. Clearly, reuse of blades and non-sterilization of instruments creates a risk of person-to-person transmission of bloodborne infection $[7,14]$. Blade reuse and risk of transmission of diseases with similar practices have also been reported from surveys of barbers in Turkey and India $[9,18]$. Barbers in Pakistan and elsewhere also carry out other very risky procedures such as circumcision, incisions and wound drainage $[19,20]$.

Our study has several important strengths, including the use of random sampling of the listed population of barbers in the whole city, face-to-face administration of the survey questionnaire and inclusion of all the barbers working in the selected shops with a high response rate. However we also acknowledge 


\begin{tabular}{|c|c|c|c|c|}
\hline \multirow{2}{*}{ Practice item } & \multicolumn{2}{|c|}{ Yes } & \multicolumn{2}{|c|}{ No } \\
\hline & No. & $\%$ & No. & $\%$ \\
\hline Washes hands before each client & 128 & 68.8 & 58 & 31.2 \\
\hline $\begin{array}{l}\text { Cleans instruments with disinfectant } \\
\text { between clients }\end{array}$ & 141 & 75.8 & 45 & 24.2 \\
\hline Washes instruments after shaving clients & 112 & 60.2 & 74 & 39.8 \\
\hline $\begin{array}{l}\text { Washes razor with antiseptic solution } \\
\text { after use }\end{array}$ & 179 & 96.2 & 7 & 3.8 \\
\hline Uses new blade on new client & 178 & 95.7 & 8 & 4.3 \\
\hline $\begin{array}{l}\text { Washes razor with tapwater before use } \\
\text { on new client }\end{array}$ & 134 & 72.0 & 52 & 28.0 \\
\hline Disinfects skin cuts & 73 & 39.2 & 113 & 60.8 \\
\hline Uses same blade for armpit shaving & 25 & 13.4 & 161 & 86.6 \\
\hline Disposes of used blades in the garbage & 65 & 34.9 & 121 & 65.1 \\
\hline Razor cuts observed on clients & 5 & 2.7 & 181 & 97.3 \\
\hline
\end{tabular}

several limitations. Our findings may not be applicable to barbers who have shops outside Hyderabad city. Barbers may have misunderstood questions or may not have expressed their own views. Barbers may have been aware that they were being observed, and may therefore have modified their practices.

Pakistan is facing a huge burden of HBV and HCV infection. Prevention of transmission is the best strategy to deal with these diseases. Changing barbers' behaviours and practices can have a direct impact on risk reduction. If alerted to the situation, barbers might even be trained to act as community HIV/hepatitis educators because of their unique access to the general male population [22,23].

Our findings demonstrate that despite the many mass media health educational programmes regarding these diseases in Pakistan, barbers in Hyderabad had no detailed understanding of diseases caused by HBV and HCV and their mode of transmission, and employed risky practices implicated in transmitting these diseases. These results raise questions about the best possible way of correcting such gaps, for example with educational and promotional strategies tailored to this target group. Information should be focused on the different modes of transmission and the fact that HBV is a vaccinepreventable disease whereas no vaccine is available to prevent HCV. Further studies are required to assess the effect of interventions and how to enhance awareness among this target group.

\section{Acknowledgements}

This study was part of an investigation that received technical and financial support from the joint WHO Eastern Mediterranean Region (EMRO), Division of Communicable Diseases (DCD) and the WHO Special Programme for Research and Training in Tropical Diseases (TDR):TDR.6/3, T5/72/6, the EMRO/TDR Small Grants Scheme for Operational Research in Tropical and other Communicable Diseases.

\section{References}

1. Hepatitis B. Fact sheet no. 204. World Health Organization [website]. (http://www.who.int/mediacentre/factsheets/ fs204/en/, accessed 26 July 2010).

2. Hepatitis C. Fact sheet no. 164. World Health Organization [website]. (https://apps.who.int/inf-fs/en/fact164.html, accessed 26 July 2010).

3. Zuberi SJ. Seroepidemiology of HBV and HCV in Pakistan. International Hepatology Communications, 1996, 5:19-26.

4. Parker SP, Khan HI, Cubitt WD. Detection of antibodies to hepatitis $\mathrm{C}$ virus in dried blood samples from mothers and their offspring in Lahore, Pakistan. Journal of Clinical Microbiology, 1999, 37:2061-2063.

5. Alam MM et al. Serology based disease status of Pakistani population infected with hepatitis B virus. BMC Infectious Diseases, 2007, 7:1-4.

6. Mele A et al. Beauty treatment and risk of parenterally transmitted hepatitis: results from the hepatitis surveillance system in Italy. Scandinavian Journal of Infectious Diseases, 1995, 27:441-444.

7. Sawayama $Y$ et al. Hepatitis $C$ virus infection in institutionalized psychiatric patients: possible role of transmission by razor sharing. Digestive Diseases and Sciences, 2000, 45:351-356.
8. Habib M. Hepatitis $C$ virus infection in a community in the Nile Delta: risk factors for seropositivity. Hepatology, 2001, 33:248-253.

9. Candan F et al. Prevalence of hepatitis B and C virus infection in barbers in the Sivas region of Turkey. Occupational Medicine, 2002, 52(1):31-34.

10. She SL et al. Aseroepidemiologic study of hepatitis B virus infection among barbers in Huangshi City, Hubei, China. Microbiology and Immunology, 1988, 32:229-233.

11. Candan F et al. Prevalence of hepatitis B and C virus infection in barbers in the Sivas region of Turkey. Occupational Medicine, 2002, 52:31-34.

12. Tumminelli $F$ et al. Shaving as a potential source of hepatitis $C$ virus infection. Lancet, 1995, 327:638.

13. Zahraoui-Mehadji $M$ et al. Risque infectieux lie au sang chez les coiffeurs-barbiers traditionnels et leurs clients au Maroc [Infectious risks associated with blood exposure for traditional barbers and their customers in Morocco]. Sante, 2004, 14(4):211-216.

14. Bari $A$ et al. Risk factors of hepatitis $C$ virus infection in male adults in Rawalpindi-Islamabad, Pakistan. Tropical Medicine and International Health, 2001, 6(9):732-738. 
15. Khattak $\mathrm{MN}$ et al. Factors influencing hepatitis $\mathrm{C}$ virus seroprevalence among blood donors in north west Pakistan. Journal of Public Health Policy, 2008, 29(2):207-225.

16. Shazi L, Abbas Z. Comparison of risk factors for hepatitis B and $\mathrm{C}$ in patients visiting a gastroenterology clinic. Journal of the College of Physicians and Surgeons of Pakistan, 2006, 16(2):104-107.

17. Akhtar S et al. Epidemiologic study of chronic hepatitis B virus infection in male volunteer blood donors in Karachi, Pakistan. BMC Gastroenterology, 2005, 5:26.

18. Khandait DW, Ambadekar NN, Vasudeo ND. Knowledge and practices about HIV transmission among barbers of Nagpur city. Indian Journal of Medical Science, 1999, 53(4):167-171.

19. Janjua NZ, Nizamy MA. Knowledge and practices of barbers about hepatitis $B$ and $C$ transmission in Rawalpindi and
Islamabad. Journal of Pakistan Medical Association, 2004, 54(3):116-119.

20. Hardy DB. Cultural practices contributing to the transmission of human immunodeficiency virus in Africa. Reviews of Infectious Diseases, 1987, 9:1109-1119.

21. Khuwaja AK, Qureshi R, Fatmi Z. Knowledge about hepatitis $\mathrm{B}$ and $\mathrm{C}$ among patients attending family medicine clinics in Karachi. Eastern Mediterranean Health Journal, 2002, 8(6):787-793.

22. John JK. Country watch: India. AIDS/STD Health Promotion Exchange, 1995, 3:7-8.

23. Howard J. Raising a chorus of voices to prevent HIV. Harvard AIDS Review, 1995, Fall:12-13.

\section{The Weekly Epidemiological Record}

The Weekly Epidemiological Record (WER) serves as an essential instrument for the rapid and accurate dissemination of epidemiological information on cases and outbreaks of diseases under the International Health Regulations and on other communicable diseases of public health importance, including emerging or re-emerging infections.

An electronic bilingual English/French version of the WER is accessible every Friday and can be downloaded free of charge. For information on subscription to the printed edition, visit the WHO Periodicals site or use the mail address: World Health Organization, WHO Press, 20 Avenue Appia, CH-1211 Geneva 27. WER can also be accessed online at: http://www.who.int/wer/en/ 